\title{
IMPORTANCIA DE LA FUNCIÓN NOTARIAL EN LA PROTECCIÓN DE LOS DERECHOS FUNDAMENTALES EN EL CONTEXTO DEL COVID-19
}

\author{
Jessica María De Vettori González* \\ Universidad de Lima, Lima, Perú \\ jessica@notariadevettori.com
}

Recibido: 7/9/2020 Aprobado: 14/9/2020

doi: https://doi.org/10.26439/iusetpraxis2021.n052.5068

\begin{abstract}
RESUMEN. El mundo vive una situación sui generis con la actual crisis y mortandad que causa el COVID-19. Sus consecuencias han incidido en todas las esferas de nuestra sociedad y el mundo del derecho no ha sido ajeno, porque las personas, a pesar de las restricciones personales o impuestas para evitar el contagio, tienen que seguir con su vida, sus acciones y sus relaciones dentro del ámbito jurídico. Aunque muchos operadores se han resistido por múltiples motivos a seguir laborando, hay una institución que mantiene su presencia activa: la función notarial. Todos los notarios han puesto su mejor esfuerzo para dar cumplimiento al servicio esencial que se les ha conferido para el ejercicio y tutela de los derechos fundamentales. La función notarial, sin perder su esencia, que es la de dar fe pública y autenticidad a los actos y contratos que ante el notario se celebran, viene utilizando la tecnología adaptándola a los requerimientos actuales y actuando frente a esta nueva realidad originada por la pandemia, tanto en su relación con los usuarios como con el Estado, manteniendo siempre su esencia y el respeto a sus principios.
\end{abstract}

PALABRAS CLAVE: función notarial / seguridad jurídica / pandemia / resiliencia / derechos fundamentales

\footnotetext{
* Magíster en Derecho Empresarial por la Universidad de Lima y magíster en Derecho Registral y Notarial por la Universidad San Martín de Porres. Se desempeña como notaria y ejerce la docencia en la Universidad de Lima.
} 


\section{IMPORTANCE OF THE NOTARIAL FUNCTION FOR PROTECTING THE FUNDAMENTAL RIGHTS IN THE CONTEXT OF COVID-19}

ABSTRACT. The world is living a sui generis situation due to the current crisis and mortality caused by COVID-19. Its consequences have affected all spheres of our society, including the world of law, because people, despite self-imposed limits or restrictions imposed by others to avoid the transmission of the virus, have to continue with their lives, actions and relationships within the legal field. Even though many legal practitioners were reluctant for multiple reasons to continue working, one service remained active: the notarial function. All the notaries made their best efforts to comply with the main function conferred to them for exercising and protecting people's fundamental rights. The notarial function, without losing its nature, which consists in attesting and authenticating the acts and contracts handled before a notary public, has been using the technology in its relationship with both users and the State by adapting it to the current requirements in the face of the new reality caused by the pandemic, and always maintaining its nature and respect for its principles.

KEYWORDS: notarial function / legal certainty / pandemic / resilience / fundamental rights 


\section{LA FUNCIÓN DEL NOTARIO}

El notario es por definición, de acuerdo con la Ley del Notariado, el profesional del derecho que en forma privada está autorizado como tercero imparcial para "dar fe", es decir, valor de verdad a los actos y contratos que ante él se celebren. El notario de tipo latino, tanto a nivel internacional como nacional, a través de la fe pública y del riguroso respeto de las formas vela por la seguridad jurídica.

El primer párrafo del artículo 2 del Decreto Legislativo del Notariado manifiesta que "el notario es aquel profesional del derecho que está autorizado para dar fe de los actos y contratos que ante él se celebran" (Decreto Legislativo N. ${ }^{\circ} 1049,2008$ ). Al respecto, Valderrama (2020) señala que la función que este artículo le otorga al notario debe ser concatenada con lo expuesto en el artículo 24 del mismo texto normativo, puesto que, según este último, "los instrumentos públicos notariales con arreglo a lo dispuesto en la ley producen fe respecto a la realización del acto jurídico y de los hechos y circunstancias que el notario presencie".

El notario formaliza la voluntad, redactando y confiriendo autenticidad a los instrumentos que él elabora. Conserva los originales y expide traslados; su función comprende también la comprobación de hechos y la tramitación de asuntos no contenciosos. Cabe resaltar que, en esencia, el notario es un "asesor" para poder configurar la voluntad de quienes solicitan su ministerio y, para ello, se vale de los principios que lo rigen e inspiran y que son el eje de su actuación diaria. Concordamos por eso con lo precisado por Castro (2019) cuando destaca que la función notarial:

Tiene como fines específicos la seguridad al asignar la certeza al documento notarial; la permanencia al utilizar los procedimientos adecuados para que el documento sea indeleble y el valor como el grado de eficacia para producir efectos jurídicos. (Sección de Análisis, párr. 3)

Asimismo, en cuanto a la función notarial, Vallet de Goytisolo (1978) señala lo siguiente:

La función del notario en el tráfico negocial está encaminada consiguientemente a velar por la seguridad jurídica de los actos, ya sean constitutivos, de entidades jurídicas o de derechos, o bien traslativos de bienes o constitutivos de gravámenes. Estos negocios, como todos los hechos jurídicos, producen el tránsito de una situación jurídica inicial a otra situación jurídica final. (p. 192)

Por último, este autor expresa: "La vida negocial sana requiere su ajustamiento a derecho y la seguridad de que se dé cumplimiento correcto a lo dispuesto o a lo convenido" (Vallet de Goytisolo, 1978, p. 184). 


\section{SEGURIDAD JURÍDICA QUE OTORGA EL NOTARIO}

Como los diversos operadores del derecho, el notario tiene una contribución significativa a otorgar la seguridad jurídica, principio que transita todo nuestro ordenamiento jurídico aspirando a la prosperidad de la justicia y al bien común. Para cumplir con dichos preceptos, tiene vías bien definidas, como darle forma legal a la voluntad de las personas que acuden a él, ajustando dicha voluntad a la legalidad que se plasma en un documento notarial sólido, que le otorga al documento caracteres legales que lo convierten en indeleble permitiendo la paz social. Como bien señala Armella (2013), este es " [e]l sentido de nuestra vocación y la razón de ser de una lucha diaria que significa consolidar ese principio en las relaciones entre los particulares y de los particulares con los poderes del Estado" (p. 71).

Más aún, cuando irrumpe en una determinada sociedad un cambio legislativo que modifica profundamente los paradigmas anteriores atendiendo a ciertas necesidades humanas, es necesario trabajar en pos de detectar las flaquezas que su aplicación acarrea y consolidar soluciones que alejen esos riesgos, antes que pretender su derogación (Armella, 2013, p. 71).

Mantilla (2018) afirma que el sector notarial ha tenido un gran avance en cuanto a sus atribuciones, tanto es así que

[l]as facultades de los notarios son exclusivas de estos funcionarios, tomando en cuenta que el notario, al estar investido de fe pública, brinda seguridad jurídica a todos los actos que se realicen en su presencia, convirtiéndolo en el candidato idóneo para asignar cada vez más facultades respecto a procedimientos no contenciosos en varias áreas del derecho. (p. 122)

El notario es, pues, el profesional investido de la fe pública y otorga seguridad jurídica de todos los actos expuestos ante él. Es agente del derecho y, por lo tanto, conoce las normas propias del derecho civil y registral. Es una persona de ciencia, pero también de conciencia, y debe saber llegar y recoger las solicitudes y necesidades de las personas adecuándolas a la ley y a la verdad, pues su función es esencialmente la búsqueda de la verdad, es decir, de lo correcto, la búsqueda constante del bien y de la satisfacción, finalmente, del deber cumplido.

\section{EL CUMPLIMIENTO DE LA FUNCIÓN DEL NOTARIO EN TIEMPOS DE PANDEMIA}

El notario, en la búsqueda de la verdad, debe saber hacer una "desinfección" (en términos actuales) de todo virus que pretenda ir contra su naturaleza y contra el respeto de los derechos fundamentales de las personas. Dicho accionar concatena con lo señalado por la Constitución Política del Perú de 1993, cuyo artículo 44 resalta los deberes del Estado de salvaguardar la plena vigencia de los derechos humanos, norma que se interpreta 
conforme a los instrumentos internacionales. Gran parte de los derechos fundamentales son aquellos derechos humanos positivados en las constituciones estatales. Parafraseando a Aragón (2011), en efecto, "toda norma emanada del poder constituido está compelida a observar los derechos; los hombres mediante la Constitución confían su gobierno al Estado porque mediante la Constitución el Estado queda obligado a respetar la libertad" (p. 148). Los derechos fundamentales son valiosos en la medida que cuentan con garantías procesales que permiten accionarlos no solo ante los tribunales, sino también ante la administración e incluso entre los particulares.

Hoy nos valemos de alcohol, geles, fumigaciones, lámparas de rayos ultravioleta, entre otros, para tener un lugar limpio, libre del virus que causa el COVID-19, que hoy nos aqueja. El notario, metafóricamente, a lo largo de su historia tiene que hacer el mismo trabajo de desinfección de los documentos que él redacta y en los actos en que participa para librarlos y limpiarlos de todo vicio de ilegalidad, valiéndose del cumplimiento de la Constitución y las leyes, así como de sus principios. De esta manera, puede conseguir la finalidad que el derecho notarial persigue, que es la seguridad jurídica, y, por ende, aspirar a la paz social.

Estoy convencida de que el notario per se es y debe ser, por su naturaleza, un instrumento de paz social. Para ello, debe cumplir con respetar y ejercer su función cumpliendo con sus principios de respeto, probidad, veracidad, transparencia, honestidad, responsabilidad, autenticidad, respeto a las personas y al ordenamiento jurídico, objetividad, imparcialidad, y respeto a la dignidad de los derechos de las personas, la Constitución y las leyes.

El fin social notarial consiste sencillamente en acercar la paz al derecho siendo parcial e independiente, a través de la argumentación jurídica y profesional que el notario, desde hace tiempo, está preparado para brindar. Si a las virtudes notariales que plantean ser imparcial e independiente se añaden las que emergen de los ya referidos deberes éticos notariales de legalidad, información, asesoramiento y consejo, y ni qué decir de los deberes éticos de transparencia y gratitud, todo ello en la tutela de los intereses subjetivos que se consolidan en respeto de la autonomía de la voluntad protegida sustancialmente a través del ejercicio de la dación de la fe notarial, la ecuación del derecho justo se presenta definitivamente como práctica ineludible y de indispensable tratamiento. La contribución notarial a la sociedad es plena y permanente (Cosola, 2013, p. 235).

Compartimos la responsabilidad notarial más aún en esta etapa de pandemia producida por el COVID-19, tanto en el ámbito privado (que dicta hacer lo que es correcto y prohíbe hacer algo en contra de lo que uno cree que está permitido) como en la relación con los usuarios (que nos inspiran a prestar nuestros servicios en forma creativa) y en el compromiso con nuestro colegio profesional y en nuestro deber de colaboración con el Estado. 


\section{EL RESPETO A LA DIGNIDAD DE LAS PERSONAS}

La dignidad humana es el punto de referencia de todas las facultades que se dirigen al reconocimiento y la afirmación de la dimensión trascedente y moral del ser humano. Fue Kant (2002) quien introdujo elementos nuevos en el concepto de dignidad humana que, sin lugar a dudas, representan la máxima guía: "Lo digno es aquello que no tiene precio, que nadie puede ser tratado como un medio, o que la humanidad es en sí misma una dignidad" (p. 115).

La dignidad es un derecho fundamental que, junto con los otros derechos, es la piedra angular sobre la cual descansa la superestructura jurídica de las democracias. Todos los seres humanos merecemos un trato digno sin ningún tipo de discriminación con igualdad de oportunidades, sancionando acciones moralmente incorrectas que atenten contra sus derechos fundamentales.

El notario es el operador jurídico que convive con las actividades y necesidades diarias de la población, y es el encargado directo de la protección de la dignidad de las personas a través del respeto a los derechos fundamentales en las voluntades que él adecúa al marco jurídico en los instrumentos públicos notariales que redacta. Para ello, equipara a las partes por las fallas que puedan existir en el mercado, por las diversas desventajas que pueda tener una persona frente a otra o por la vulnerabilidad en que una o más personas puedan encontrarse.

La protección de la dignidad implica el respeto a los derechos fundamentales. El notario debe crear los mecanismos para alcanzar la paz social y garantizar la seguridad jurídica respetando la libertad, haciendo posible la toma de decisiones y la adecuación de las mismas al marco jurídico, equilibrando a las partes. De esta manera, persigue la finalidad del derecho que -como nosotros concebimos-está conformada por un trinomio indesligable que es la libertad, la justicia y la paz.

\section{EL PRINCIPIO DE HUMANIDAD}

Como resaltamos en el apartado anterior, las palabras personas, dignidad y derechos de la persona toman un cariz especial en este tiempo de pandemia. El notario debe actuar a la altura de estas circunstancias y estar de pie en todo momento, al frente de esta batalla contra un enemigo invisible, pero que afecta a toda la sociedad en su conjunto. Él tiene que ser el general que guíe con las correctas estrategias a su entorno.

Consideramos que es en esta situación cuando debe aparecer -y definitivamente se está desarrollando en la práctica- otro principio notarial inmerso en los demás, que hoy podemos llamar el principio de humanidad. Este principio notarial cobra vital importancia en las circunstancias actuales y debe ser el estandarte de todos los principios, puesto que lleva como eje central las respuestas a emergencias, orientadas a salvar vidas y 
aliviar el sufrimiento en el caso de una guerra o de un desastre antrópico. Ahora, con la pandemia del COVID-19, estamos ante una guerra y frente a un enemigo invisible que es el SARS-CoV-2, virus que genera enfermedad y, en muchos casos, la muerte.

Por ello, el principio de humanidad es la bandera que debe enarbolarse en el notariado, pues el notario tiene que ser un instrumento de paz social para las personas que desean, a través de medios creativos y de supervivencia en esta etapa de reinicio paulatino de actividades económicas, seguir realizando sus actos civiles y comerciales. Ya sea mediante la disposición de sus bienes, adquiriendo y realizando nuevos emprendimientos, o con renegociaciones de contratos, o llegando a transacciones de la mejor forma posible, lo que buscan las personas es salir adelante, seguir desarrollando sus respectivas personalidades y proyectos de vida, e incluso prevenir que podrán continuar con el desarrollo de sus personalidades aun si se encontrasen en alguna situación en que no puedan expresar su voluntad por problemas de salud y no ver sus derechos fundamentales desprotegidos. Es aquí donde surge con más fuerza la figura jurídica del apoyo, que lo que busca como figura de protección familiar es que las personas que tengan alguna discapacidad, o puedan tenerla a futuro, puedan contar con una figura de "asistencia" que les permita cumplir con su proyecto de vida y con el establecimiento de las correspondientes salvaguardias en los instrumentos que el notario redacta.

El notario recoge las voluntades de las personas en los instrumentos públicos que diseña y redacta de acuerdo con la situación concreta de cada una; incluso recoge disposiciones en testamentos que se cumplirán y surtirán efectos luego de fallecidas las personas. Su rol asesor toma una fuerza particular por las condiciones de pandemia que crean necesidades especiales para las personas que acuden a un notario, afectados por un problema de salud, económico, social o político.

La proyección del ser humano después de su vida, es decir, lo que le gustaría que se cumpla luego de fallecido, se cumple a través del otorgamiento de un testamento, que es un acto jurídico unilateral que contiene la declaración de última voluntad, con disposiciones de contenido patrimonial y/o extrapatrimonial, en la que el testador dispone y administra de algún modo la herencia futura de sus herederos y/o legatarios cumpliendo las formalidades que la ley exige. El testamento surtirá efectos a la muerte del testador.

En todo lo antes mencionado, el principio de humanidad es la bandera que enarbola y engrandece la función notarial como instrumento de protección y promoción de la dignidad humana, entendida esta última como principio-derecho. Como bien lo ha desarrollado el Tribunal Constitucional:

La dignidad de la persona humana constituye un valor y un principio constitucional portador de valores constitucionales que prohíbe, consiguientemente, que aquella sea un mero objeto del poder del Estado o se le dé un tratamiento instrumental. Pero la dignidad también es un dínamo de los derechos fundamentales; por ello, 
es parámetro fundamental de la actividad del Estado y de la sociedad, así como la fuente de los derechos fundamentales. De esta forma la dignidad se proyecta no solo defensiva o negativamente ante las autoridades y los particulares, sino también como un principio de actuaciones positivas para el libre desarrollo de la persona y de sus derechos. (STC. Exp. N. ${ }^{\circ}$ 10087-2005-PA/TC, 2007, fundamento jurídico 5)

A su vez, de la fuerza inminente que toma este principio surgen otros dos principios dentro del COVID-19 que complementan al principio en mención. Estos son el principio de empatía y el principio de resiliencia.

Mediante el principio de empatía, el notario debe comprender y adecuarse a las nuevas situaciones que viven las personas que acuden a él. Así como en el principio de imparcialidad el notario debe equilibrar a las partes para que ambas tengan las mismas opciones de comprensión y puedan tomar sus decisiones (por ejemplo, dando más tiempo a la parte con menos conocimientos), ahora más que nunca debe ponerse en el lugar de la persona que acude a él, tomando en cuenta el entorno y la realidad de la pandemia del COVID-19, y darle toda la asesoría que esté a su alcance e incluso aquella que pudiese conseguir, pues aquí la empatía alcanza los diversos aspectos personales y emocionales del ser humano que se encuentra inmerso en una pandemia.

\section{EL PRINCIPIO DE RESILIENCIA}

Este principio se complementa con el principio del respeto y busca mecanismos que coadyuven al cumplimiento de su función sin desnaturalizarla. Así, el notario puede utilizar los medios tecnológicos digitales que estén a su alcance y cualquier ciencia que puede ayudarle a comprender mejor la situación en que se encuentra la persona que solicita el servicio notarial.

El principio de resiliencia implica que, frente a las dificultades que afronten en forma diaria tanto los usuarios como el notario, este último debe transmitir y ayudar como instrumento de paz en su entorno, aun en situaciones muy difíciles de los usuarios y del propio notario.

La resiliencia puede manifestarse en situaciones en las que existe un riesgo importante, debido a la acumulación de factores de estrés y de tensiones. Asimismo, surge cuando la persona es capaz de conservar aptitudes en situaciones de riesgo y continuar un crecimiento armonioso. Puede aparecer también cuando se produce la cura de uno o de varios traumas y, como consecuencia, un resultado feliz (Vargas y Montalvo, 2017, p. 28).

El notario, aun frente a todo el riesgo y situaciones penosas de las que pueda tomar conocimiento, le toca "ser resiliente" para poder ser un verdadero instrumento de paz. 
Es como un general en una batalla que está al mando de un ejército, tiene que buscar estrategias y soluciones dándole valentía y seguridad a su tropa.

\section{CONCLUSIÓN}

No estábamos preparados para hacer frente a los efectos y las consecuencias de la pandemia. Esta ha cambiado la vida de los países y, por ende, la vida de los ciudadanos, ya que estamos en una crisis nunca antes vista y con serios problemas económicos, sociales y políticos; peor aún, no sabemos qué nos depara el futuro, pero la vida continúa y tenemos que seguir adelante con actitud positiva. Una de las formas más activas de nuestra vida es nuestro desenvolvimiento en la esfera jurídica. Es allí donde necesitamos a los operadores del derecho privados o públicos. Es donde encontramos al notario.

Este es el gran reto que hoy vive el notariado peruano en el contexto de la pandemia. Día a día expone su vida junto con todo su equipo de trabajo, convencido del rol y de la misión que le toca cumplir en este contexto del COVID-19, así como de que la función notarial es un servicio esencial para la sociedad para el ejercicio y protección de los derechos fundamentales.

Por ello, me permito decir que el notario, además de ser un hombre de ciencia y de conciencia, es un hombre de resiliencia.

\section{REFERENCIAS}

Aragón, M. (2011). Derechos fundamentales y su protección. Temas básicos de derecho constitucional. Valencia: Tirant lo Blanch.

Armella, C. (2013). La ley de identidad de género en la República de Argentina y su ámbito en el derecho notarial y registral. Los derechos humanos de las minorías y la seguridad jurídica del tráfico internacional. En L. B. Pérez Gallardo y M. A. Arévalo (Coords.), Escritos sobre derecho notarial. Libro homenaje a Carlos Enrique Becerra Palomino. Lima: Gaceta Notarial.

Castro, J. (23 de octubre del 2019). La seguridad jurídica en el derecho notarial. El Sol de Durango. Recuperado de https://www.elsoldedurango.com.mx/analisis/laseguridad-juridica-en-el-derecho-notarial-4358487.html

Cosola, S. (2013). El concepto del derecho notarial a la luz de la naturaleza de la función. (Diálogos entre Vallet de Goytisolo y Von Ihering). En L. B. Pérez Gallardo y M. A. Arévalo (Coords.), Escritos sobre derecho notarial. Libro homenaje a Carlos Enrique Becerra Palomino (pp. 225-246). Lima: Gaceta Notarial. 
Decreto Legislativo N. ${ }^{\circ}$ 1049, Decreto Legislativo del Notariado. (25 de junio del 2008). Recuperado del sitio web del Ministerio de Justicia y Derechos Humanos: https://www.minjus.gob.pe/wp-content/uploads/2017/04/Decreto-LegislativoN\%C2\%BA-1049.pdf

Kant, I. (2002). Fundamentación para una metafísica de las costumbres. Madrid: Alianza Editorial.

Mantilla, K. (2018). El matrimonio civil en sede notarial (tesis de licenciatura). Universidad Central del Ecuador, Quito, Educador. Recuperado de http://www.dspace.uce. edu.ec/handle/25000/16571

Sentencia recaída en el Expediente N. ${ }^{\circ}$ 10087-2005-PA/TC. (2007). Tribunal Constitucional del Perú. Recuperado de https://www.tc.gob.pe/jurisprudencia/2007/100872005-AA.pdf

Valderrama, J. G. (7 de mayo del 2020). ¿Se puede legislar la contratación electrónica y ser tutelada a través de la función notarial?: una nueva necesidad a raíz de la COVID-19. La Ley. El Ángulo Legal de la Noticia. Recuperado de https://laley. pe/art/9678/se-puede-legislar-la-contratacion-electronica-y-ser-tutelada-atraves-de-la-funcion-notarial-una-nueva-necesidad-a-raiz-de-la-covid-19

Vallet de Goytisolo, J. (1978). La función notarial de tipo latino. Revista de Derecho Notarial, n. ${ }^{\circ} \mathrm{C}, 183-198$.

Vargas, J., y Montalvo, A. (2017). Proceso de resiliencia para la superación de riesgos sociales en los niños, niñas y adolescentes de la ONG Gema-Huancayo 1990-2016 (tesis de licenciatura). Universidad Nacional del Centro del Perú. Recuperado de http://repositorio.uncp.edu.pe/handle/UNCP/3920 